\title{
Development and Validation of an Information Leaflet on Oral Care for Irradiated Patients
}

This article was published in the following Dove Press journal:

Patient Preference and Adherence

Helene Bacher ID
Ramona Schweyen (D)
Dirk Vordermark (iD)
Bernd Leplow
Jeremias Hey iD
'Department of Dental Prosthetics,
University Hospital Halle/Saale, Halle
(Saale), Germany; ${ }^{2}$ Clinic for
Radiotherapy, University Hospital Halle/
Saale, Halle (Saale), Germany; ${ }^{3}$ Institute
of Psychology,Martin Luther University
Halle-Wittenberg, Halle (Saale), Germany

Correspondence: Helene Bacher Universitätsklinikum Halle (Saale), Universitätsklinik und Poliklinik für

Zahnärztliche Prothetik, Magdeburger Str.

16, Halle (Saale) 06I I2, Germany

Tel +49345 5573777

Fax +49345 5573779

Email helene.mueller@uk-halle.de
Purpose: The aim of the study was to develop an optimally designed and comprehensibly formulated patient information leaflet (PIL) to improve patients' memory of information provided by physicians during a radiotherapy (head and neck area) consultation. This PIL was tested on unaffected probands for its usefulness in clinical practice.

Patients and Methods: A panel of experts compiled the main topics using Lawshe's content validity ratio. Flesch's Reading Ease Score (FRE) and the Baker Able Leaflet Design (BALD) index were adapted to appropriate values to determine text comprehensibility and graphic design. The evaluation involving unaffected participants (231 men, 380 women, 21 not specified; mean age $=32 \pm 13.63$ years, range $=18-79$ years) was conducted based on three questionnaires for four groups of respondents with varying prior knowledge of the subject. When answering the questionnaires, only half the participants had access to the PIL. Results: The expert panel included 59 out of 75 proposed topics. After reformulations, the FRE was adjusted from 38.5 to 51.4. The BALD index ranged from 24 to 26 , depending on the printout edition. The evaluation of 632 unaffected participants indicated a difference in the correctly answered items that ranged from $2.86 \%$ to $30.76 \%$ between participants with and without access to the PIL.

Conclusion: The general guidelines for the design of written patient information material were met. The evaluation of unaffected volunteers resulted in an advantage by answering the questionnaires after receiving the PIL. This study supports health practitioners in the development, design, and evaluation of written information material using scientific methods. An evaluation should be performed on affected patients.

Keywords: patient education, cancer, surveys and questionnaires, oral hygiene, information dissemination, patient satisfaction

\section{Introduction}

Providing comprehensive medical information is essential to actively involve patients in the decision-making process on health issues. Doctor-patient consultations are the basis for all therapeutic interventions. ${ }^{1}$ The verbal communication of information to patients is of major importance because it is directly tailored to their current needs and gives them the opportunity to ask concrete questions. ${ }^{2-4}$ Disadvantages, such as misunderstood information and resulting uncertainties, can arise from a lack of communication between doctors and patients. ${ }^{5}$ Additionally, there are misconceptions about the ability of patients to receive information from consultation with physicians, to understand technical terms, and to follow the information flow. ${ }^{6,7}$ Studies show that the use of patient information leaflets (PILs) as a support in doctor-patient consultations leads to increased knowledge compared to doctor-patient consultations without leaflets. 8 ,9 
Providing patients with written information material has advantages for physicians and patients. PILs can help prevent misunderstandings and ensure the communication of information independently of the doctor. The use of PILs in combination with doctor-patient consultation improves patients' memory of essential information, satisfaction, and compliance. ${ }^{6}$ Additionally, written information can be used for an unlimited number of times as a reference to remember relevant topics during the treatment process. $^{2}$

Therefore, the optimal design of PILs is necessary to communicate pertinent information effectively. ${ }^{10,11}$ Because of these positive characteristics, PILs are created for many medical branches; however, they are often published without prior evaluation and vary significantly in quality. ${ }^{12}$ Ideally, PILs should be designed and pre-examined according to scientific guidelines. ${ }^{11}$ Consequently, in cooperation with several university hospitals, we developed a PIL concerning oral and dental care in the context of radiotherapy for the head and neck area and tested its usability and information provision. Its design and readability were examined based on scientific guidelines and the knowledge gain was evaluated on groups of probands with varying prior knowledge about the topic.

\section{Patients and Methods Design of the PIL Content}

A panel of experts - 12 physicians (oral and maxillofacial surgery and radiotherapy) and dentists from different university hospitals - created the PIL content. To compile relevant topics regarding PIL content, recent literature in German and English concerning prophylaxis and side effects of radiotherapy of the head and neck area was analyzed, thematically subdivided, and summarized. The relevance of the main topics was determined in a referendum of the panel of experts using Lawshe's method. ${ }^{13}$

\section{Flesch's Reading Ease Score (FRE)}

After the contents of the PIL had been formulated, their readability was determined using the FRE for texts in German.

\section{PIL Design}

The leaflet was designed in accordance with guidelines for the design of PILs with Adobe Illustrator (Adobe Systems Software Ireland Limited, Dublin, Ireland) to enable the print of the PIL in different formats. Subsequently, the PIL was evaluated by a third person using the BALD index; ${ }^{14}$ for this purpose, certain design elements concerning layout, font, line spacing, images and choice of words were scored. The maximum number of points was 32 .

\section{PIL Evaluation}

\section{Questionnaires}

Three different questionnaires $(\mathrm{A}-\mathrm{C})$ were developed to determine the amount of information conveyed by the PIL. The main topics of questionnaire A (21 items) were dental pre-treatment, side effects during radiotherapy, and handling of protheses during radiotherapy. Questionnaire B (19 items) covered handling the radiation splints, mucositis, and dental care concerning radiotherapy. Questionnaire C (18 items) included xerostomia, nutrition during radiotherapy, and dental care concerning radiotherapy.

The items were available as hypotheses, which could be answered by the probands with "right" or "wrong." To determine the questionnaire characteristics, the index of difficulty, the variance, and the item-total correlation were calculated. Pearson-Bravais was used for correlation coefficients. Cronbach's $\alpha$ was used to define the internal consistency of the questionnaires. Questionnaire evaluation was conducted on the groups that had no access to the PIL.

\section{Probands}

Groups of probands with different levels of prior knowledge about the topic and the contents of the PIL were interviewed. The minimum number of participants per group were 20, based on the previous sample size calculation. Exclusion criteria for all groups were completed medical studies and/ or a planned, current or completed radiotherapy in the head and neck area. Group 1 included dentistry students in clinical (6th-10th) semesters. Group 2 included students of dentistry in pre-clinical (1st-5th) semesters and excluded students of group 1. Group 3 consisted of students from other disciplines who had not completed or begun medical or dental studies. Group 4 included patients of the Clinic for Dental Prosthetics of the University Clinic Halle-Wittenberg who also did not meet the inclusion criteria of the other groups.

All students interviewed were enrolled in a course of study at Martin Luther University, Halle-Wittenberg, Germany. Participants were recruited by a person not involved in the study process (groups 1-3) or in the treatment process (group 4). Prior knowledge of the topic was rated highest in group 1 and lowest in group 4.

The investigations were conducted between February 2012 and March 2013 in cooperation with the Institute of Psychology of the Martin Luther University Halle-Wittenberg. Half the participants in each study 
group were given a PIL by random allocation. Thereafter, 24-96 h later, a randomly assigned questionnaire was distributed to all probands. No personal data were recorded. Consent to voluntary participation resulted in submitting the anonymously completed questionnaire at a time independent of the receipt of the questionnaire. Owing to the complete anonymity, it was impossible to withdraw from the study after questionnaire submission.

The study was conducted in accordance with the Declaration of Helsinki (2013) and based on the conduct of medical research in accordance with ethical principles. The medical faculty's ethics committee at the Martin Luther University Halle-Wittenberg approved the study protocol for the subsequent investigation on actually affected patients (reference number 2017-119). Because it was a one-time, completely anonymous pre-trial of uninvolved probands no ethics vote was required.

\section{Data Analysis}

The data from the evaluation of the PIL were digitalized and analyzed using SPSS (IBM, Ehningen, Germany) and Excel (Microsoft, Redmond, USA). To check the data for normality, the Kolmogorov-Smirnov test with significance correction according to Lilliefors was performed. Furthermore, $t$-tests, Mann-Whitney $U$-tests, and Kruskal-Wallis tests were performed to calculate significant differences. A p-value below 0.05 was considered significant.

\section{Results \\ PIL Design \\ Content}

The panel of experts voted on the previously proposed topics. Of the 75 topics, 59 were included in the PIL content. The main topics compiled by the panel of experts and their evaluation based on Lawshe's procedure were the indication for radiotherapy, the side effects of the radiotherapy and how to avoid them and how to deal with them, the procedure of the dental pre-treatment, and the care of the mouth during and after radiotherapy. Excluded were topics such as the medical basics of radiotherapy and organizational details (Table 1). When topics were rated very relevant by panelists, they were formulated in more detail in the PIL and highlighted with the help of highcontrast text fields and associated graphic illustrations.

\section{Readability Score}

After analysis of the information from the literature, the readability score for German language was 38.5. By reformulating and adapting the choice of words, the readability score was changed to 51.4 (Table 2).

\section{Design \\ Design Characteristics}

The design of the PIL was based on current guidelines for the design of patient information material. Vector graphics were used to enable printing in various formats. The layout was prepared in several colors varying between main text, additional information and very relevant sections. There were 20 multi-colored schematic illustrations and four black and white pictograms. These were placed next to the corresponding text passages.

\section{BALD Index}

The BALD index of the PIL depends on its print format. The BALD index is 24 in size A6, and 26 in size A4 (Table 3).

\section{Evaluation of the PIL Questionnaires}

The average item difficulty was 0.63 . The average variance of the items was 0.184 . The average index of discrimination was 0.18 . Cronbach's $\alpha$ s for questionnaires A$\mathrm{C}$ were $0.786,0.739$, and 0.611 , respectively.

\section{Evaluation}

\section{Descriptive Statistics}

The number of probands was split up among groups of different levels of prior knowledge (Table 4). Table 5 presents an overview of the descriptive statistics of the study population. The mean age differed significantly between all groups (Analysis of variance; $p<0.001$, Levene's test; $p<0.001$; post hoc Bonferroni $p<0.05$ ).

\section{Testing of Knowledge}

The mean numbers of correctly answered items for questionnaires A-C are shown in Table 6. Figure 1 shows the results of the three questionnaires relating to respondents' previous knowledge. The average difference between the groups with and without access to the PIL was $18.4 \%$. In all groups of probands, a high percentage of correctly answered items was evident when access to the PIL was provided. In questionnaire $\mathrm{C}$, the difference to the group without access to the PIL was non-significant in the groups of patients and dental students in pre-clinical semesters. The previous knowledge of the different groups had an influence on the percentage of correctly answered items (Kruskal-Wallis test; $p<0.001$ ), both in the group with access to the PIL (Mann-Whitney 
Table I Results of the Panel of Experts' Voting on the Main Topics of the Patient Information Leaflet

\begin{tabular}{|c|c|c|c|c|}
\hline Topic & Essential & $\begin{array}{l}\text { Useful, but Not } \\
\text { Essential }\end{array}$ & Irrelevant & $\begin{array}{l}\text { Content } \\
\text { Validity Ratio }\end{array}$ \\
\hline Medical basic knowledge of radiotherapy & 7 & 2 & 3 & 0.16 \\
\hline Indication for radiotherapy & 11 & I & 0 & 0.83 \\
\hline Combination of radiotherapy with operation or chemotherapy & 6 & 2 & 4 & 0 \\
\hline Side effects & 12 & 0 & 0 & 1 \\
\hline Xerostomia & 12 & 0 & 0 & I \\
\hline Taste loss & 12 & 0 & 0 & I \\
\hline Mucositis & 12 & 0 & 0 & 1 \\
\hline Increased risk for candida infections & 9 & 2 & 1 & 0.5 \\
\hline Radiation caries & 12 & 0 & 0 & 1 \\
\hline Osteoradionecrosis & 12 & 0 & 0 & 1 \\
\hline \multicolumn{5}{|l|}{ Dental pre-treatment } \\
\hline Extraoral examination & 9 & I & 2 & 0.5 \\
\hline Dental examination & 12 & 0 & 0 & 1 \\
\hline Dental radiograph & 12 & 0 & 0 & 1 \\
\hline Professional dental cleaning & 12 & 0 & 0 & 1 \\
\hline Impressions for radiation splints & 12 & 0 & 0 & 1 \\
\hline Dental pre-therapy (fillings, deep scaling, etc.) & 8 & 3 & 1 & 0.33 \\
\hline Indications for teeth extractions & 12 & 0 & 0 & I \\
\hline Importance of daily oral hygiene & 12 & 0 & 0 & 1 \\
\hline Dental care during radiotherapy & & & & 1 \\
\hline Regular even in cases of sulcus bleeding and pain & 12 & 0 & 0 & 1 \\
\hline Gum line & 12 & 0 & 0 & 1 \\
\hline Interdental spaces & 12 & 0 & 0 & 1 \\
\hline Soft toothbrush & 12 & 0 & 0 & 1 \\
\hline Palate/tongue massage & 12 & 0 & 0 & 1 \\
\hline Possibility to clean teeth without toothpaste & 11 & 1 & 0 & 0.83 \\
\hline Cleaning methods & 8 & 2 & 2 & 0.33 \\
\hline Cleaning the toothbrush with Chlorhexidine solution & 12 & 0 & 0 & 1 \\
\hline \multicolumn{5}{|l|}{ Handling removable dentures } \\
\hline No dentures during the radiotherapy & 12 & 0 & 0 & I \\
\hline Handling/storage & 12 & 0 & 0 & 1 \\
\hline Start of dental rehabilitation three months after completion of therapy & 11 & 0 & 0 & 0.83 \\
\hline \multicolumn{5}{|l|}{ Radiation splints as radiation protection } \\
\hline Radiation scatter & 12 & 0 & 0 & 1 \\
\hline Cleaning/care/storage & 11 & 1 & 0 & 0.83 \\
\hline Handling & 11 & 1 & 0 & 0.83 \\
\hline \multicolumn{5}{|l|}{ Radiation splints for fluoride application } \\
\hline Effect & 12 & 0 & 0 & 1 \\
\hline Fluoride application & 12 & 0 & 0 & 1 \\
\hline Period of application & 11 & I & 0 & 0.83 \\
\hline Handling & 10 & 1 & 1 & 0.67 \\
\hline Cleaning/care/storage & 10 & 2 & 0 & 0.67 \\
\hline Restoration by the dentist if necessary & 8 & 4 & 0 & 0.33 \\
\hline \multicolumn{5}{|l|}{ Mucositis } \\
\hline Adequate dental care & 12 & 0 & 0 & 1 \\
\hline Mouth rinses with water, saline solution, or sage tea & 12 & 0 & 0 & I \\
\hline No chamomile & 11 & 0 & 1 & 0.83 \\
\hline Ice cubes & 12 & 0 & 0 & 1 \\
\hline Pineapple & 12 & 0 & 0 & 1 \\
\hline
\end{tabular}

(Continued) 
Table I (Continued).

\begin{tabular}{|c|c|c|c|c|}
\hline Topic & Essential & $\begin{array}{l}\text { Useful, but Not } \\
\text { Essential }\end{array}$ & Irrelevant & $\begin{array}{l}\text { Content } \\
\text { Validity Ratio }\end{array}$ \\
\hline Pilocarbin & 8 & 1 & 3 & 0.33 \\
\hline Painkillers & 8 & 4 & 0 & 0.33 \\
\hline Abstinence from alcohol and nicotine & 9 & 3 & 0 & 0.5 \\
\hline \multicolumn{5}{|l|}{ Xerostomia } \\
\hline Stimulate salivation & 12 & 0 & 0 & I \\
\hline Water uptake & 11 & I & 0 & 0.83 \\
\hline Saline flush & 11 & 1 & 0 & 0.83 \\
\hline Sugar free candy and chewing gum & 12 & 0 & 0 & I \\
\hline Saliva substitute & 12 & 0 & 0 & I \\
\hline Vaseline for lips and corners of the mouth & 11 & 1 & 0 & 0.83 \\
\hline \multicolumn{5}{|l|}{ Trismus } \\
\hline Exercise & 9 & 1 & 2 & 0.5 \\
\hline Physiotherapy & 9 & 3 & 0 & 0.5 \\
\hline \multicolumn{5}{|l|}{ Nutrition } \\
\hline Small meals & 12 & 0 & 0 & I \\
\hline Water uptake & 12 & 0 & 0 & I \\
\hline Vitamin A rich juices & 12 & 0 & 0 & I \\
\hline Edible oil with fruit juices & 12 & 0 & 0 & 1 \\
\hline Low acid fruit and vegetables & 12 & 0 & 0 & 1 \\
\hline Milk products (calcium) & 12 & 0 & 0 & I \\
\hline More fish than meat & 12 & 0 & 0 & I \\
\hline Fibers & 11 & 0 & I & 0.83 \\
\hline Mild spices & 10 & 0 & 2 & 0.67 \\
\hline Tube feeding if necessary & 9 & 2 & 1 & 0.5 \\
\hline \multicolumn{5}{|l|}{ Aftercare } \\
\hline Appointments with radiotherapists/operation aftercare/dental follow-up & 8 & 2 & 2 & 0.33 \\
\hline
\end{tabular}

Note: Dark shaded fields indicate topics that have not been included in the content of the PIL.

Table 2 Readability Score (FRE: Flesch-Reading-Ease)

\begin{tabular}{|l|l|l|l|l|}
\hline & Sentences & Words & Syllables & FRE $_{\text {German }}$ \\
\hline Version I & 94 & 1.313 & 2.863 & 38.5 \\
Version 2 & 127 & 1.254 & 2.548 & 51.4 \\
\hline
\end{tabular}

$U$-test; $\mathrm{p}<0.001)$ and in the group without access to the PIL (Mann-Whitney $U$-test; $\mathrm{p}<0.001$ ).

\section{Discussion}

\section{PIL Design}

Content

Clinical studies show that patients can take in only a limited amount of information from consultations with doctors. ${ }^{15}$ Factors such as high psychological stress and increased stress levels have a negative effect on recall. ${ }^{16}$ Contrastingly, providing written information in addition to verbal information can positively influence information communication. ${ }^{8,9}$
However, this requires the provision of an appropriate amount of information. The scope of PILs varies and can range from a single page to multi-part booklets. ${ }^{12}$ The investigated PIL was arranged on 12 pages. This allows for a manageable reading time of about 10 minutes. As prepared, the information can ideally serve both as therapy preparation and as support in dealing with short- and longterm side effects. If the doctor providing the information uses the PIL during the consultation, it serves both as illustrative material and as a guide to address all relevant topics. Furthermore, the information material can be provided to patients prior to consultations, thus allowing time to prepare questions and stay engaged in the discussion.

However, during the discussion of relevant topics by panelists from different fields, the amount of information was reduced to only the essential aspects. When reducing the written information, it must be remembered that it is always combined with a medical consultation. Thus, there 
Table 3 Design Characteristics of the Patient Information Leaflet

\begin{tabular}{|l|l|l|}
\hline \multirow{2}{*}{ Design Characteristics } & \multicolumn{2}{|l|}{ Value } \\
\cline { 2 - 3 } & A6 & A4 \\
\hline Lines 50-89 mm & I & 0 \\
Separation between lines & I & 3 \\
Lines unjustified & I & I \\
Serif typeface & 0 & 0 \\
Type size & 2 & 3 \\
First line indented & 0 & 0 \\
Titles (headings) lower case & I & 1 \\
Italics & 0 & 0 \\
Positive advice (“do" instead of "do not”) & 2 & 2 \\
Headings stand out & 2 & 2 \\
Numbers are all Arabic & I & 1 \\
Boxed text & I & 1 \\
Pictures (not including cover pictures) & 3 & 3 \\
Number of colors & 3 & 3 \\
White space & 3 & 3 \\
Paper quality & 3 & 3 \\
Total & 24 & 26 \\
\hline
\end{tabular}

is no claim to completeness; however, the effort to convey essential information in an appropriate scope is maintained.

\section{Readability Score}

A readability index quantifies how easily text is read. In general, an increase in readability leads to a better memory of the content of the text and a shorter reading time. ${ }^{7}$ Difficult text generally has an index of 30-50, while medium difficulty text is between 50 and 70 . In general, a higher readability index of over 70 is targeted for comparable PILs. ${ }^{17}$

The readability index of the original version of the text was originally 38.5 . We obtained an index of 51.4 by rewording and changing the choice of words. When using this index to optimize text, the comprehensibility and readability of text are not always directly correlated. Text comprehension, which is more important than readability per se, is influenced by other factors such as readers' competence, motivation, interest in the subject matter, and prior knowledge. $^{7}$ The reading competence of the intended target group should not be underestimated; otherwise, readers with a high level of reading competence might be disinterested in the information. Motivation to the PIL should be rated as high, as the information has been adapted the target group. Adequate prior knowledge of the readers can also be expected through the combination with the medical clarification interview. In this context, the adapted readability index to the intended field of application of the information material was appropriate. Accordingly, the readability index should always be combined with the individual assessment by an expert reader and should not be used as the sole indicator of text comprehensibility. ${ }^{18}$

Table 4 Groups and Number of Probands

\begin{tabular}{|l|l|l|l|l|l|l|l|}
\hline \multirow{2}{*}{ Group } & \multicolumn{2}{l|}{ Questionnaire A } & \multicolumn{2}{l|}{ Questionnaire B } & \multicolumn{2}{l|}{ Questionnaire C } & \multicolumn{2}{l|}{ Total } \\
\cline { 2 - 8 } & Access to PIL & No Access to PIL & Access to PIL & No Access to PIL & Access to PIL & No Access to PIL \\
\hline 1 & 25 & 25 & 25 & 25 & 26 & 24 & 150 \\
2 & 26 & 25 & 27 & 27 & 23 & 26 & 26 \\
3 & 23 & 22 & 30 & 27 & 30 & 31 & 154 \\
4 & 29 & 24 & 30 & 26 & 30 & 109 & 170 \\
Total & 103 & 96 & 112 & 105 & $\mathbf{1 0 9}$ & $\mathbf{6 3 2}$ \\
\hline
\end{tabular}

Abbreviation: PIL, patient information leaflet.

Table 5 Descriptive Statistics of the Probands

\begin{tabular}{|c|c|c|c|c|c|c|c|c|}
\hline \multirow[t]{3}{*}{ Group } & \multirow{2}{*}{\multicolumn{2}{|c|}{ Age }} & \multicolumn{6}{|l|}{ Sex } \\
\hline & & & \multicolumn{2}{|c|}{ Male } & \multicolumn{2}{|c|}{ Female } & \multicolumn{2}{|c|}{ No information provided } \\
\hline & $\mathbf{M}$ & SD & $\mathbf{n}$ & $\%$ & $\mathbf{n}$ & $\%$ & $\mathbf{n}$ & $\%$ \\
\hline Dentistry students & 24.66 & 3.53 & 122 & 40.1 & 176 & 57.9 & 6 & 2.0 \\
\hline Students from other disciplines & 29.10 & 11.67 & 29 & 18.4 & 119 & 75.3 & 10 & 6.3 \\
\hline Patients & 46.73 & 15.70 & 80 & 47.1 & 85 & 50.0 & 5 & 2.9 \\
\hline Total & 31.96 & 13.63 & 231 & 36.6 & 380 & 60.1 & 21 & 3.3 \\
\hline
\end{tabular}

Abbreviations: PIL, patient information leaflet; SD, standard deviation; $n$, number. 
Table 6 Percentage of Correctly Answered Items

\begin{tabular}{|c|c|c|c|c|c|c|}
\hline \multirow[t]{2}{*}{ Group } & \multicolumn{2}{|l|}{ No Access to the PIL } & \multicolumn{2}{|l|}{ Access to the PIL } & \multirow{2}{*}{$\begin{array}{l}\text { Mean } \\
\text { Difference }\end{array}$} & \multirow[t]{2}{*}{$\mathbf{p}$} \\
\hline & $\begin{array}{l}\text { Percentage of Correctly Answered } \\
\text { Items }\end{array}$ & SD & $\begin{array}{l}\text { Percentage of Correctly Answered } \\
\text { Items }\end{array}$ & SD & & \\
\hline \multicolumn{7}{|c|}{ Questionnaire A } \\
\hline I & 76.17 & 9.04 & 83.50 & 10.58 & 7.33 & $<0.001$ \\
\hline 2 & 59.38 & 15.46 & 84.03 & 16.61 & 24.65 & $<0.001$ \\
\hline 3 & 62.12 & 17.15 & 77.54 & 13.57 & 15.45 & 0.002 \\
\hline 4 & 52.43 & 16.62 & 83.19 & 19.37 & 30.76 & $<0.001$ \\
\hline \multicolumn{7}{|c|}{ Questionnaire B } \\
\hline I & 64.42 & 12.65 & 87.79 & 15.69 & 23.37 & $<0.001$ \\
\hline 2 & 57.69 & 11.19 & 88.11 & 12.77 & 30.42 & $<0.001$ \\
\hline 3 & 54.58 & 9.92 & 81.05 & 13.30 & 26.47 & $<0.001$ \\
\hline 4 & 48.99 & 13.87 & 75.44 & 13.28 & 26.45 & $<0.001$ \\
\hline \multicolumn{7}{|c|}{ Questionnaire C } \\
\hline I & 73.61 & 15.65 & 88.89 & 9.56 & 15.28 & $<0.001$ \\
\hline 2 & 68.80 & 12.77 & 71.74 & 18.12 & 2.94 & 0.436 \\
\hline 3 & 69.26 & 10.18 & 83.98 & 9.34 & 14.72 & $<0.001$ \\
\hline 4 & 58.07 & 15.64 & 60.93 & 13.80 & 2.86 & 0.258 \\
\hline
\end{tabular}

Abbreviations: PIL, patient information leaflet; SD, standard deviation; p, p-value.

\section{Design}

After the elaboration and formulation of relevant topics for the PIL, an appropriate form is essential to arouse the interest of the target group. The graphic representation of important facts was used to make them easier to comprehend by abstraction. In other studies, pictograms led to improved information recall ${ }^{19}$. The design of the PIL was adapted to the capacity of different readers to absorb information according to topic relevance. The BALD index was applied to the two proposed formats, which displayed above-average results. ${ }^{20}$

\section{Evaluation of the Questionnaires Questionnaires}

The questionnaire characteristics followed the recommended guidelines for statistical testing. ${ }^{21}$ The internal consistency of the questionnaires is relatively low. Considering the relatively ease simplicity of some of the items of the questionnaires that could be answered correctly by many participants, the low Cronbach's alpha can be explained. These items were intentionally left in the questionnaire because the main purpose was to convey basic knowledge rather than to distinguish between educational marks, which would be the aim of classical examinations.

\section{Evaluation}

The mean age of randomly selected non-affected patients was lower than the mean age of patients previously treated with head and neck radiation $($ women $=66.2 \mathrm{yr}$, men $=$ $63.8 \mathrm{yr}$ ). ${ }^{22}$ Similarly, most patients surveyed were women, contrasting the large proportion of male patients with head and neck cancer. ${ }^{22}$ Although our sample differs from cases, a certain comparability of the ability to remember information from written material is assumed. Although the interviews were conducted with German-speaking patients, a general transfer of the procedure compared to the procedure in other regions is possible within our limitations.

The evaluation of the participants showed a higher percentage of correctly answered items in all groups with access to the PIL, confirming the benefit of written information material. ${ }^{8,9,12}$ The mean difference of the group of the unaffected patient group was comparable to that of similarly structured studies. ${ }^{23}$ The difference in the average percentage of correctly answered items between the groups with and without access to the PIL varied between the questionnaires. In the first two questionnaires, a clear difference was noticeable; for questionnaire $\mathrm{C}$, no significant difference was found between groups 2 and 4. Possibly the topic "nutrition" in questionnaire $\mathrm{C}$ could have influenced the result. While the 


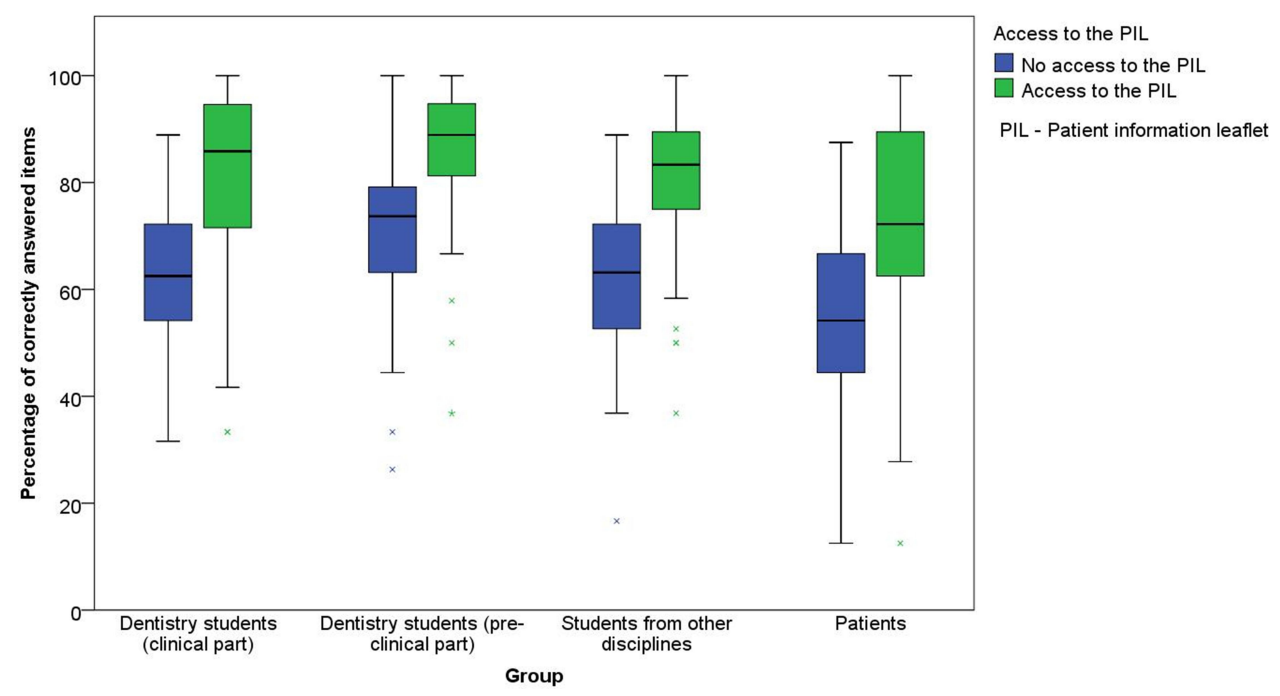

Figure I Percentage of correctly answered items on questionnaires A, B, and C.

other topics were specifically related to the course of radiotherapy, this topic is also part of general education. Participants' attitude toward this topic is conditioned by psychosocial influences; therefore, the items were not answered only with the help of the knowledge gained from the PIL. ${ }^{24}$ The prior knowledge of the groups had an influence on the percentage of correctly answered items, both in the group that had received the PIL and in the group that had not. Our findings indicate that the PIL is helpful in conveying knowledge and, in combination with the prior knowledge from doctor-patient consultations, it improves patients' comprehension of information even further.

\section{Conclusion}

Although PILs are created for many medical fields, they are often published without prior evaluation and vary considerably in quality. The developed PIL was created in accordance with the requirements of the guidelines for the design of patient information material. Among the groups of participants without previous specific knowledge, the average difference in the percentage of correctly answered items with and without access to the PIL was 19.4\%. This PIL can therefore be used as an adequate supplement to educational consultations. This study shows the great importance of pre-evaluation for the implementation of an adequate PIL and informs health practitioners in the preparation, design and evaluation of written information material. An evaluation of patients treated with radiotherapy in the head and neck area should follow.

\section{Disclosure}

The authors declare that they have no conflicts of interest for this work.

\section{References}

1. Dettmeyer R. Medizin \& Recht. Rechtliche Sicherheit für den Arzt. 2., vollständig überarbeitete und ergänzte Auflage. Berlin: Springer; 2006. Springer E-book Collection.

2. Pollock K, Cox K, Howard P, Wilson E, Moghaddam N. Service user experiences of information delivery after a diagnosis of cancer: a qualitative study. Support Care Cancer. 2008;16(8):963-973. doi:10.1007/s00520-007-0363-3

3. Davey HM, Armstrong BK, Butow PN. An exploratory study of cancer patients' views on doctor-provided and independent written prognostic information. Patient Educ Couns. 2005;56(3):349-355. doi:10.1016/j.pec.2004.03.010

4. Jabbour J, Milross C, Sundaresan P, et al. Education and support needs in patients with head and neck cancer: a multi-institutional survey. Cancer. 2017;123(11):1949-1957. doi:10.1002/cncr.30535

5. Fitchett RC, Aldus EJ, Fitchett LR, Cross J. The lived experience of head and neck cancer patients receiving curative radiotherapy: a systematic review and meta-ethnography. Psycho-Oncology. 2018;27(9):2077-2086. doi:10.1002/pon.4790

6. Kessels RPC. Patients' memory for medical information. $J R$ Soc Med. 2003;96(5):219-222. doi:10.1258/jrsm.96.5.219

7. Ley P. Communicating with Patients - Improving Communication, Satisfaction and Compliance. Stanley Thornes: Cheltenham; 1998.

8. Humphris GM, Field EA. The immediate effect on knowledge, attitudes and intentions in primary care attenders of a patient information leaflet: a randomized control trial replication and extension. $\mathrm{Br}$ Dent J. 2003;194(12):683-688. doi:10.1038/sj.bdj.4810283

9. van der Meulen N, Jansen J, van Dulmen S, Bensing J, van Weert J. Interventions to improve recall of medical information in cancer patients: a systematic review of the literature. Psycho Oncol. 2008;17(9):857-868. doi:10.1002/pon.1290

10. John H, Hale ED, Treharne GJ, et al. Patient evaluation of a novel patient education leaflet about heart disease risk among people with rheumatoid arthritis. Musculoskelet Care. 2011;9(4):194-199. doi: $10.1002 / \mathrm{msc} .207$ 
11. Coulter A, Entwistle V, Gilbert D. Sharing decisions with patients: is the information good enough? Br Med J. 1999;318(7179):318-322. doi:10.1136/bmj.318.7179.318

12. Sustersic M, Gauchet A, Foote A, Bosson J-L. How best to use and evaluate patient information leaflets given during a consultation: a systematic review of literature reviews. Health Expect. 2017;20 (4):531-542. doi:10.1111/hex.12487

13. Lawshe $\mathrm{CH}$. A quantitive approach to content validity. Pers Psychol. 1975;28:563-575. doi:10.1111/j.1744-6570.1975.tb01393.x

14. Baker SJ. Who can read consumer product information? Aust J Hosp Pharm. 1997;27(2):126-131. doi:10.1002/jppr1997272126

15. McGuire LC. Remembering what the doctor said: organization and adults' memory for medical information. Exp Aging Res. 1996;22 (4):403-428. doi:10.1080/03610739608254020

16. Tarsia M. Implicit and explicit memory biases in mixed anxietydepression. J Affect Disord. 2003;77(3):213-225. doi:10.1016/S01650327(02)00119-2

17. Meyer MF, Bacher R, Roth KS, Beutner D, Luers JC. Systematic analysis of the readability of patient information on websites of German nonuniversity ENT hospitals. HNO. 2014;62(3):186-195. doi:10.1007/s00106-013-2799-8.
18. Klare GR. Judging readability. Instr Sci. 1976;5(1):55-61. doi:10.10 07/BF00120230.

19. Houts PS, Bachrach R, Witmer JT, Tringali CA, Bucher JA, Localio RA. Using pictographs to enhance recall of spoken medical instructions. Patient Educ Couns. 1998;35(2):83-88. doi:10.1016/ S0738-3991(98)00065-2

20. Mathew EM, Rajiah K, Sharma KK. Consumer's perception on design and layout of consumer medical information leaflets on obesity and lipid lowering drugs. J Clin Diagn Res. 2013;7 (12):2800-2802. doi:10.7860/JCDR/2013/6468.3762

21. Möltner A, Schellberg D, Jünger J. Basic quantitative analysis of medical examinations. GMS Z Med Trainer. 2006;23:3.

22. Barnes B, Kraywinkel K, Nowossadeck E, et al. Bericht zum Krebsgeschehen in Deutschland 2016. Berlin: Robert Koch Institut; 2016.

23. Humphris GM, Duncalf M, Holt D, Field EA. The experimental evaluation of an oral cancer information leaflet. Oral Oncol. 1999;35(6):575-582. doi:10.1016/S1368-8375(99)00040-8

24. Robinson E, Blissett J, Higgs S. Social influences on eating: implications for nutritional interventions. Nutr Res Rev. 2013;26(2):166-176. doi:10.1017/S0954422413000127
Patient Preference and Adherence

\section{Publish your work in this journal}

Patient Preference and Adherence is an international, peer-reviewed, open access journal that focusing on the growing importance of patient preference and adherence throughout the therapeutic continuum. Patient satisfaction, acceptability, quality of life, compliance, persistence and their role in developing new therapeutic modalities and compounds to optimize clinical outcomes for existing disease

\section{Dovepress}

states are major areas of interest for the journal. This journal has been accepted for indexing on PubMed Central. The manuscript management system is completely online and includes a very quick and fair peer-review system, which is all easy to use. Visit http:// www.dovepress.com/testimonials.php to read real quotes from published authors. 